\title{
Non-surgical Management of Endodontic Periradicular Pathosis - A Clinical Research
}

\author{
Tahmeena Ishrat Ahmed ${ }^{1}$, Mujibur Rahman Howlader ${ }^{2}$ \\ ${ }^{1}$ Lecturer, Department of Conservative Dentistry, Dhaka Dental College, Mirpur-14, Dhaka, Bangladesh, ${ }^{2}$ Associate Professor, Department of \\ Conservative Dentistry \& Endodontics, Faculty of Dentistry, BSMMU, Shahbag, Dhaka, Bangladesh.
}

\begin{abstract}
:
Background: In most cases the aetiological factors of periradicular diseases are oral contaminants through the root canal or degenerating pulpal tissues. Therefore, the mere surgical removal of the periapical lesions without proper root canal disinfection and obturation will not result in the healing of the periradicular tissues. On the other hand, traditional surgical technique rather fearful and troublesome job due to various reasons. So successful apical and periapical repair depends on conventional root canal treatment-a non surgical procedure. Crucial to this management and ultimate success is the complete debridement of the root canal system, followed by three-dimensional obturation to seal both the apical foramen and coronal orifice. Objective: Thus, the purpose of this study was to clinically verify the possibility of management of periradicular pathosis by non-surgical conventional root canal therapy. Methods: The present study was a prospective observational study carried out in the department of Conservative Dentistry and Endodontics, Faculty of Dentistry, Bangabandhu Sheikh Mujib Medical University (BSMMU), Shahbag, Dhaka. Here, 75 cases of eondodontically involved symptomatic non-vital teeth having periradicular pathosis were managed by conventional root canal therapy. Result: After 18 months follow up with post operative clinical and radiological evaluations, in this study the final outcome was favourable-88\%, doubtful-08 \%, and failure-04\%.
\end{abstract}

Key words: Endodontics, Periarticular pathosis

[BSMMU J 2008; 1(1): 22-28]

\section{Introduction:}

Most of the endodontic periradicular pathosis are induced as a result of direct or indirect involvement of oral bacteria $^{1}$. The major pathways of pulpal contamination are exposed dentinal tubules, direct pulp exposure, lateral and apical foramen as well as blood-borne bacteria. As a result of the interaction of the microorganisms and their by-products, various nonspecific and specific mediators of inflammation and numerous living and non-living irritants harbor in the root canal system. Release of these irritants from infected root canals into periradicular tissues can initiate formation and perpetuation of periradicular lesions ${ }^{2}$. The prostaglandin and the inflammatory cytokines can activate osteoclasts, culminating in bone resorption. Radiographically, these lesions appear as radiolucent areas around the portal(s) of exit of the main canal or lateral and/or accessory canals. Histologically, the lesion consists predominantly of granulation tissue, exhibiting significant angioblastic activity, many fibroblasts, connective tissue fibers, an inflammatory infiltrate and often a connective tissue encapsulation. This tissue, replacing the periodontal ligament, apical bone, and sometimes the root cementum and dentin, is infiltrated

Address for correspondence: Dr. Tahmeena Ishrat Ahmed, Lecturer, Department of Conservative Dentistry, Dhaka Dental College, Mirpur14, Dhaka, Bangladesh. by plasma cells, lymphocytes, mononuclear phagocytes and occasional neutrophils. Occasionally cholesterol clefting is seen, as are foreign-body giant cells ${ }^{3}$. If, in addition, adjacent strands of epithelium or rests of Malassez have been stimulated by the inflammatory response to form a stratified squamous epithelium-lined cavity filled with fluid or semisolid material, a cyst may be considered to be developed. There are two distinct categories of radicular cysts-one containing cavities completely enclosed in epithelial lining does not communicate with the root canal known as true radicular cysts and another containing epithelium-lined cavities that are open to the root canals ${ }^{4,5}$ known as "bay"4 or "pocket"5 cysts.

Previously, teeth having periradicular pathology were managed by extraction or by surgical means (apisectomy) ${ }^{6}$. But recent development of endodontics indicate that teeth having periradicular pathosis can be managed by conventional root canal therapy. As long as there is passage of irritants from the root canal system, or a failure of the phagocytic macrophage system to control this irritation, simultaneous destruction and repair of periradicular tissues continued ${ }^{3}$. This concept relates to the rationale for non surgical root canal treatment as opposed to surgical intervention. The mere surgical removal, via curettage, of the reactive periradicular tissues will not address the source 
of the patient's problem, i.e. the removal of irritants from within the canal. As bacteria present in the root canal system play a fundamental role on the development and persistence of the periradicular lesions, successful treatment depends on effective removal of the irritants (inflamed or necrotic tissue) from the root canal system, followed by development of a fluid tight seal at the apical foramen, and total obliteration of the root canal system so healing and repair can take place $e^{2,7,8}$. The healing of periradicular tissues after root canal treatment is often associated with granulation tissue formation and maturation $^{2}$. The granulation tissue is infiltrated by neutrophils, lymphocytes and plasma cells, which are responsible for removal endogenous and exogenous irritants, followed by fibroblastic proliferation and collagen deposition. On the periphery of the granulation tissue, osteoblasts and osteoclasts abound. With maturation, the number of cells decreases, whereas collagen increases. Ultimately, mature bone forms from the periphery toward the center ${ }^{9}$ and cemental apposition if root resorption was present. Integrated within these events are complex cellular and immunological phenomena designed to eradicate all debris and foreign material that is counterproductive to tissue repair. When granuloma is present the course of healing is uneventful and generally follows the events described ${ }^{10}$. The healing of abscess may be slower; the exudates and bacteria must be cleared from the tissues before regeneration occurs. A variation of the abscess, the sinus tract (intraoral and extraoral) will heal following root canal treatment ${ }^{11}$. As the aim of root canal treatment is the elimination of infectious agents from the root canal and prevention of reinfection by obturation, a periapical pocket cyst is, therefore, likely to heal after this conventional endodontic therapy ${ }^{12}$. As tissue dynamics of a true cysts is selfsustaining by virtue of its independence of the presence or absence of irritants in the root canal. Therefore, the true cysts, particularly the larger ones containing cholesterol crystal, are less likely to resolve following root canal treatment ${ }^{12,13}$. True radicular cysts is less than $10 \%$ of all periapical lesions. In fact, most of the cases in which apical surgery have been performed based on radiographic diagnosis of the presence of cysts might have resolved by conventional root canal therapy.

\section{Thus, the purpose of this study was}

to clinically verify the possibility of management of periradicular pathosis by non-surgical conventional root canal therapy.

\section{Materials and method:}

This was a prospective observational study carried out in the department of Conservative Dentistry and Endodontics, Faculty of Dentistry, Bangabandhu Sheikh Mujib Medical University (BSMMU), Shahbag, Dhaka. A total 75 patients of endodontically involved infected teeth, with periradicular pathosis irrespective of age, sex and tooth numbers who fulfilled the inclusion criterias and gave consent regarding the study were selected for this study. Patients included have endodontically involved tooth with periradicular radiolucency upto $10 \mathrm{~mm}$, chronic periapical periodontitis, acute exacerbation of chronic periapical lesions, intra oral swelling with or without discharging sinus in nonvital tooth with periapical pathosis, discolored non vital tooth with radiological evidence of periradicular pathosis. Patients with endodontically infected teeth with periradicular pathosis but not included in the study when periapical radiolucency greater than 10 $\mathrm{mm}$, nonrestorable tooth, patients having degenerative bone diseases such as diabetes mellitus, hyperparathyroidism. All the patients were thoroughly interrogated about their occupation, socio economic condition, general health status, drug and past dental history. Detailed clinical, radiological examinations and pulp vitality tests were done to confirm the diagnosis. Patients symptoms, clinical signs and radiographic evidences of periapical pathosis before treatment were recorded. The presence of periradicular lesion was determined by examination of x-ray with standard magnification. Widening of the periodontal ligament space by more than $1 \mathrm{~mm}$ on at least one root was necessary to categorize the tooth having periradicular lesion. All teeth having straight-canals were instrumented with $\mathrm{H}$-files, Kfiles by conventional method and curved canal by crown down technique. Then after proper biomechanical preparation of the root canal, irrigation was done with $1 \%$ $\mathrm{NaOCI}$ solution for both the groups. All cases were treated using calcium hydroxide paste as the intracanal medicament and gutta-percha points and calcium hydroxide containing root canal sealer (Sealapex) were used for obturation of root canals. All cases were evaluated after completion of treatment at 6 month, 12 month and at 18 month. Results of the investigations were recorded and analyzed. Success, failure and doubtful were considered on evaluation criteria. A case was considered successful clinically by absence of pain, no tenderness on percussion and disappearance of swelling, sinus tract. Radiologically success was considered by disappearance or reduction of periapical lesion. On the other hand clinically failure was determined when there was no remission of symptoms that 
means persistence of pain, tenderness on percussion, swelling and sinus tract. Whereas radologically failure was considered when there was increase size of periapical lesion and development of external resorption. A case was evaluated doubtful when all other sign symptoms disappeared but size of radiolucency was stagnant.

\section{Results:}

The study involved 75 cases of endodontically involved teeth with periradicular pathosis irrespective of age, sex and tooth numbers. Among these, 70(93.33\%) cases were symptomatic presenting pain, swelling, discharging sinus and tenderness to percussion while $05(6.67 \%)$ cases were asymptomatic. (Table I)

Table-I

Preoperative clinical findings of the study subjects $(n=75)$

\begin{tabular}{lccccc}
\hline Symptomatic & Asymptomatic & Clinical & Pain on & Swelling & Discharging \\
& & Pain & Percussion & sinus & No(\%) \\
\hline No(\%) & $\mathrm{No}(\%)$ & $\mathrm{No}(\%)$ & $\mathrm{No}(\%)$ & $\mathrm{No}(\%)$ & $10(13.34 \%)$ \\
\hline $70(93.33 \%)$ & $05(6.67 \%)$ & $28(37.33 \%)$ & $30(40 \%)$ & $07(9.33 \%)$ & 100 \\
\hline
\end{tabular}

A total of $75(100 \%)$ cases had periradicular radiolucent area. Out of them, 45 (60\%) cases had periradicular radiolucent area of $\geq 5 \mathrm{~mm}$ diameter. On the other hand, $30(40 \%)$ cases had $>5 \mathrm{~mm}$ diameter of periradicular radiolucency area. (Table-II)
Table-II

Diameter of pre-operative periradicular radiolucent area $(n=75)$

\begin{tabular}{lc}
\hline$\leq 5 \mathrm{mmNo}(\%)$ & $>5 \mathrm{mmNo}(\%)$ \\
$45(60 \%)$ & $30(40 \%)$ \\
\hline
\end{tabular}

Post-operative clinical findings at 6 month, 12 month and 18 month, 27(36\%), 58(77.33\%), 67(89.33\%), cases were asymptomatic and 48(64\%), 17(22.67\%), 8(10.67\%), cases had symptoms respectively. (Table- III ).

Table-III

Post-operative clinical findings at 6 month, 12 month, 18 month $(n=75)$.

\begin{tabular}{|c|c|c|c|c|c|c|c|}
\hline & & $\begin{array}{c}\text { Symptomatic } \\
\text { No(\%) }\end{array}$ & $\begin{array}{c}\text { Asymptomatic } \\
\text { No(\%) }\end{array}$ & $\begin{array}{l}\text { Clinically } \\
\text { Pain } \\
\text { No(\%) } \\
\end{array}$ & $\begin{array}{c}\text { Pain on } \\
\text { Percussion } \\
\text { No(\%) } \\
\end{array}$ & Swelling & $\begin{array}{c}\text { Discharging } \\
\text { sinus } \\
\mathrm{No}(\%) \\
\end{array}$ \\
\hline \multirow[t]{3}{*}{ Period } & 6 month & $48(64 \%)$ & $27(36 \%)$ & 03(04\%) & $44(58.67 \%)$ & $00(00 \%)$ & $04(5.33 \%)$ \\
\hline & 12 month & 17(22.67\%) & $58(77.33 \%)$ & $00(00 \%)$ & $14(18.67 \%)$ & $00(00 \%)$ & $03(04 \%)$ \\
\hline & 18 month & $08(10.67 \%)$ & 67(89.33\%) & $00(00 \%)$ & 05(6.67\%) & $00(00 \%)$ & 03(04\%) \\
\hline
\end{tabular}

Table-IV

Post-operative radiological evaluation of periradicular radiolucency of the study subjects $(n=75)$.

\begin{tabular}{cccccc}
\hline & & Disappeared & Reduced size & Increased size & Unchanged \\
& & $\mathrm{No}(\%)$ & $\mathrm{No}(\%)$ & $\mathrm{No}(\%)$ & $\mathrm{No}(\%)$ \\
\hline Period & 6 month & $00(00 \%)$ & $39(52 \%)$ & $03(04 \%)$ & $33(44 \%)$ \\
& 12 month & $02(2.67 \%)$ & $53(70.66 \%)$ & $03(04 \%)$ & $17(22.67 \%)$ \\
& 18 month & $39(52 \%)$ & $27(36 \%)$ & $03(04 \%)$ & $06(08 \%)$ \\
\hline
\end{tabular}


Table-IV shows post-operative radiological finding after 6, 12 and 18 months of treatment.

Overall outcome of the study subjects after 18 months, based on clinical and radiological evaluation, favourable outcome was 66(88\%), doubtful 06(08\%) and failure 03(04\%), indicate that non-surgical procedure by conventional root canal therapy is effective in the management of periradicular pathosis. (Table-V).

\section{Case-1}

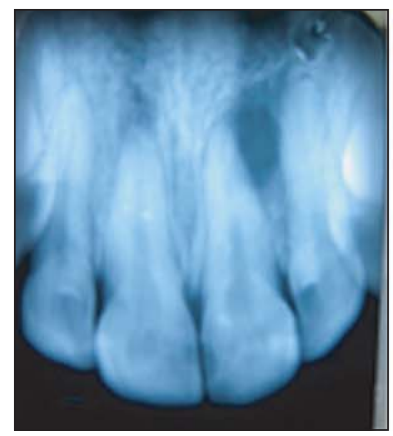

Pre-operative $X$-ray

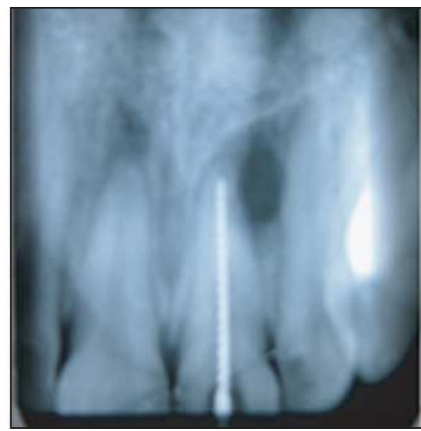

Working length measuring $X$-ray
Table-V

Final outcome of the study subjects, $(n=75)$.

\begin{tabular}{lcc}
\hline Favourable & Doubtful & Failure \\
No(\%) & No(\%) & No(\%) \\
\hline $66(88 \%)$ & $06(08 \%)$ & $03(04 \%)$ \\
\hline
\end{tabular}

Several cases show non-surgical management of endodontic periradicular pathosis. (Fig-1-6).

Fig-1: Peri-radicular pathosis managed by RCT (case-1).

\section{Case-2}

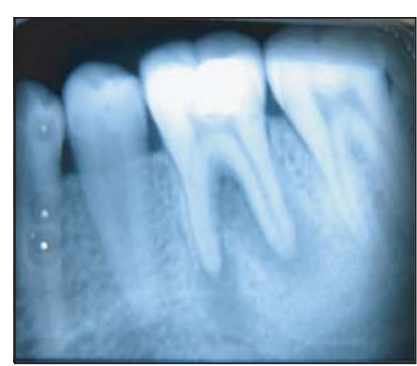

Pre-operative $X$-ray

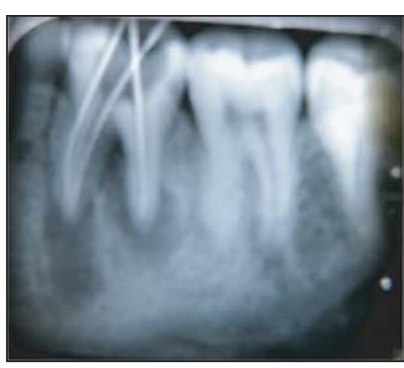

Working length measuring $X$-ray

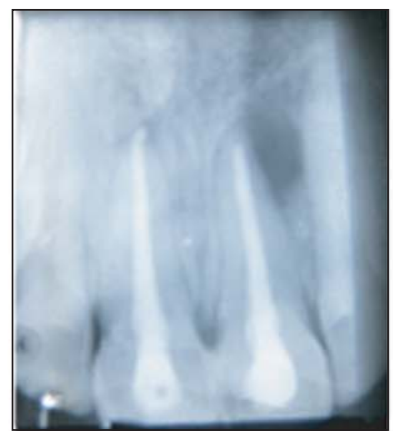

Post operative $X$-ray with periradicular lesion

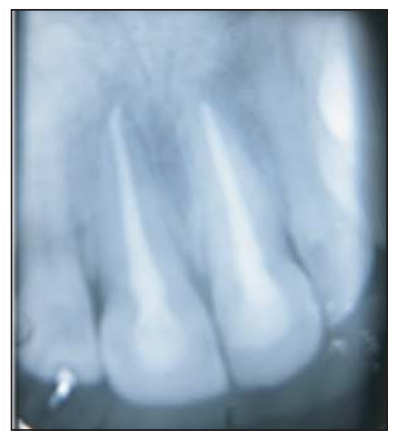

Disappearance of peri-radicular lesion after $18^{\text {th }}$ months

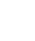

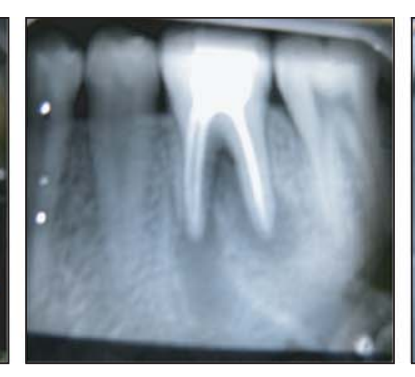

Post operative X-ray with periradicular lesion

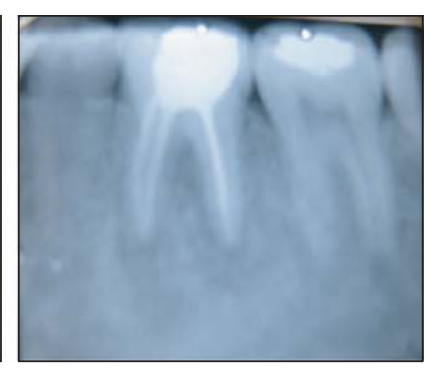

Disappearance of peri-radicular lesion after $18^{\text {th }}$ months

Fig-2: Peri-radicular pathosis managed by RCT (case-2).

\section{Case-3}

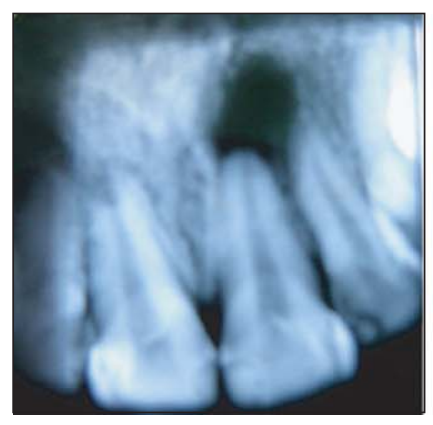

Pre-operative X-ray

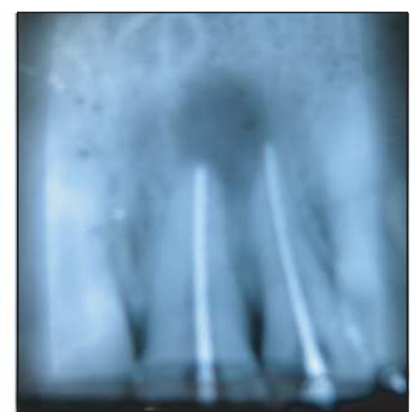

Working length measuring $X$-ray

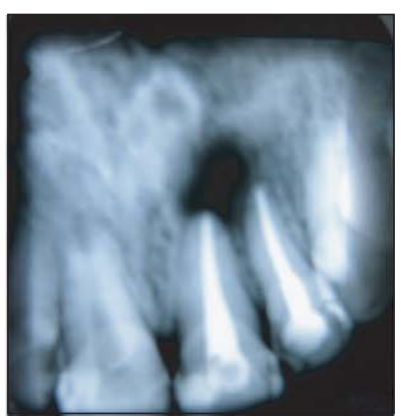

Post operative $X$-ray with periradicular lesion

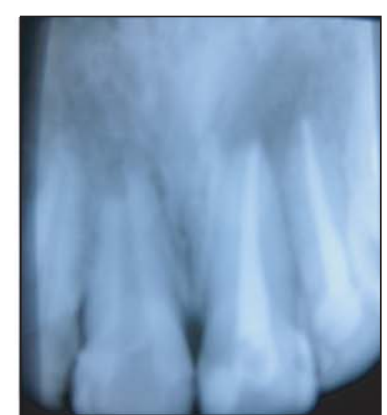

Disappearance of peri-radicular lesion after $18^{\text {th }}$ months

Fig-3: Peri-radicular pathosis managed by RCT (case-3). 


\section{Case-4}

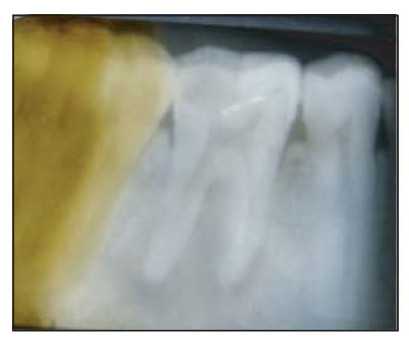

Pre-operative X-ray

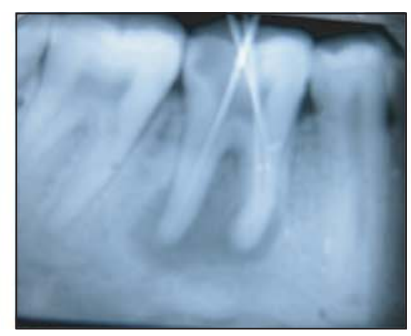

Working length measuring $X$-ray

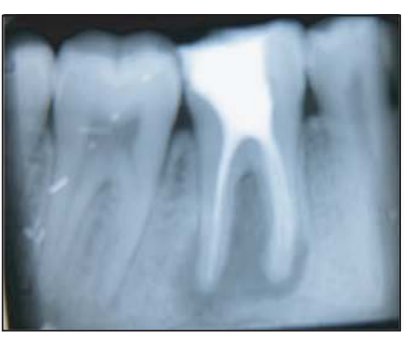

Post operative X-ray with periradicular lesion

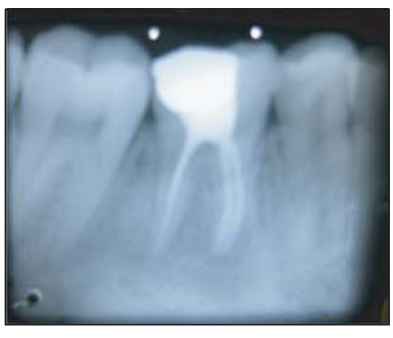

Disappearance of peri-radicular lesion after $18^{\text {th }}$ months

Fig-4: Peri-radicular pathosis managed by RCT (case-4).

\section{Case-5}

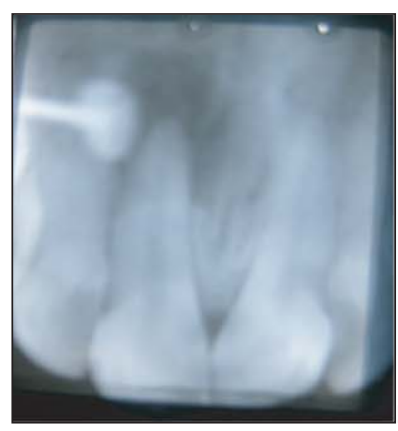

Pre-operative X-ray

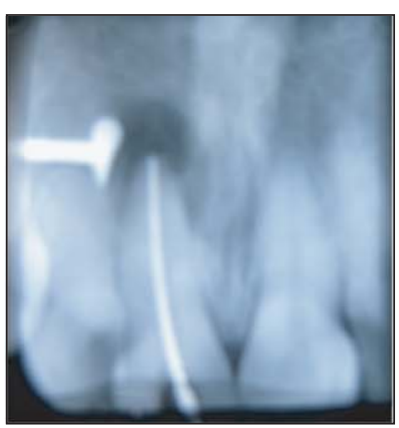

Working length measuring $X$-ray

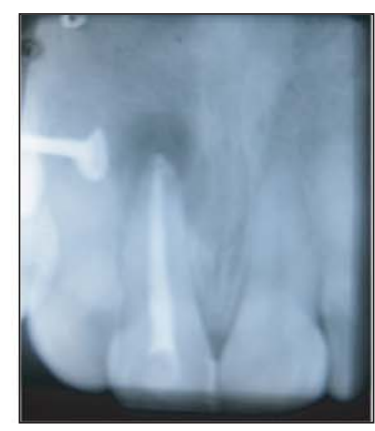

Post operative X-ray with periradicular lesion

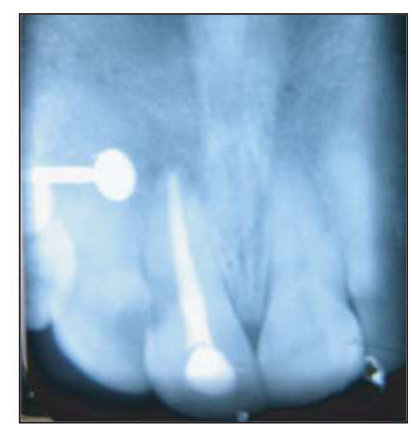

Disappearance of peri-radicular lesion after $18^{\text {th }}$ months

Fig-5: Peri-radicular pathosis managed by RCT (case-5).

\section{Case-6}

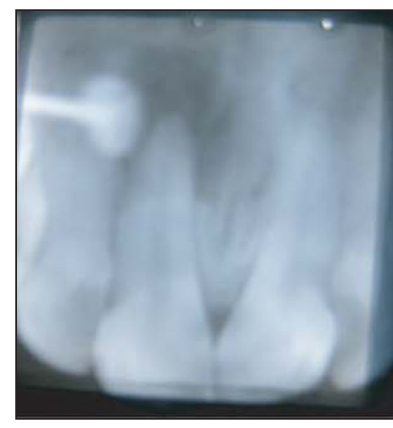

Pre-operative $X$-ray

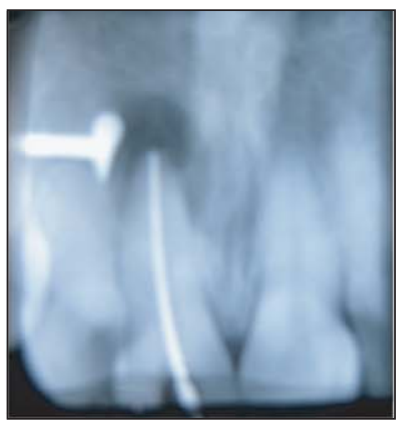

Working length measuring $X$-ray

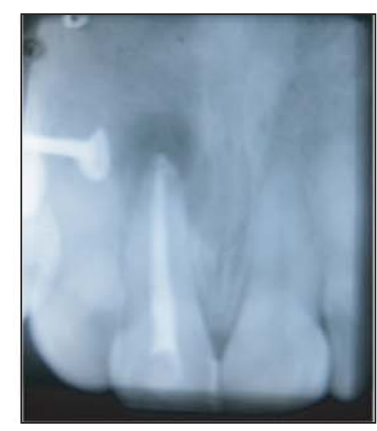

Post operative $X$-ray with periradicular lesion

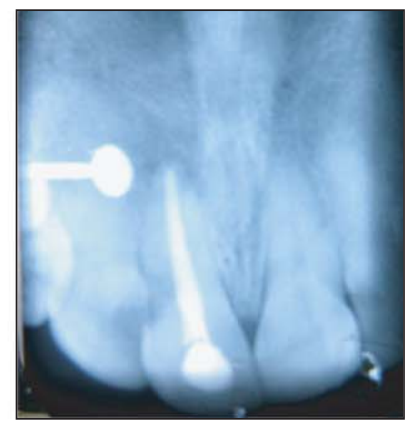

Disappearance of peri-radicular lesion after $18^{\text {th }}$ months

Fig-6: Peri-radicular pathosis managed by RCT (case-6).

\section{Discussion:}

The present study was undertaken to evaluate postoperative clinical and radiological presentations after $6,12,18$ months in the management of periradicular pathosis by non-surgical conventional root canal therapy, which have been compared to those in other similar type study reports from the different parts of the world.
Removal of irritants from the root canal system and its total obturation result in repair of inflamed periradicular tissue $^{8}$, Depending on the extent of tissue damage, repair varies from a simple reduction and resolution of inflammation to a more complex regeneration, involving remodeling of bone, periodontal ligament and cementum. Repair of the lesion, thefore, may take days to years. 
In this study after 18 months clinical and radiological evaluation showed endodontic treatment outcome was favorable in $88 \%$, doubtful in $08 \%$ and a failure in $04 \%$. In a similar type of study Suchina JA et $\mathrm{al}^{6}$ found in clinical and radiological evaluation endodontic treatment outcome was successful in $88 \%$ and $80 \%$, questionable in $10 \%$ and $15 \%$, failure in $2 \%$ and $5 \%$ respectively. In another study by Caliskan ${ }^{14}$ and Sen $\mathrm{BH}^{15}$, a total of 172 mature teeth with periapical radiolucency with or without symptoms were treated endodontically using calcium hydroxide paste as the intracanal medicament and a calcium hydroxide containing root canal sealer was used. The long term clinical and radiological outcome of this non-surgical root canal therapy, the complete healing rate was $80.8 \%$ while incomplete healing had taken place in $7.6 \%$ of the cases.

The change in size of periapical radiolucency in the followup visits was taken as the criteria for success or failure of root canal treatment. In this study, radiological evaluation of periradicular pathosis after 18 months in $52 \%$ cases radiolucency was disappeared, in 36\% cases had reduced radiolucency, in $04 \%$ cases had increased radiolucency and $08 \%$ cases had no change in radiolucency. Similar type results were also observed by Katebzadeh $\mathrm{N}$ et al ${ }^{16}$. in a study of radiographic evaluation of periradicular healing after obturation of infected root canals. This report was supported by Peter LI \& Wesselink PR ${ }^{17}$. and Kalaskar $\mathrm{R}$ et $\mathrm{al}^{18}$. In a study by $\mathrm{Oztan}^{19}$ it was found that large periapical lesions can respond favourably to non-surgical root canal treatment. This result agreed with those reported by Soares et $\mathrm{al}^{20}$, Maalouf and Gutmann ${ }^{21}$. According to Maalouf and Gutmann ${ }^{21}$, Differential radiographic criteria are unreliable for the histological diagnosis of periradicular lesions of pulpal origin. It should not, therefore, be assumed that large lesions or lesions with an opaque border are cystic. Even if cystic, or if strands of epithelium are present, repair following the removal of the source of the pathosis. In most cases, the aetiological factors of periradicular diseases are oral contaminants through the root canal or degenerating pulpal tissues. Therefore, the mere surgical removal of the lesions of pulpal origin without removing the causes through proper cleaning, shaping and obturation, will not result in the healing of the periradicular tissues. In addition to removing effectively the causative factors, enviromental changes in the periradicular tissues caused by the process of canal debridement may inherently aid in the demise of epithelium, when present. So a success rate of $80 \%$ to $90 \%$ for management of periradicular pathosis by nonsurgical root canal therapy has been recorded by many practitioners and endodontic investigators ${ }^{1,22,23}$. Success, failure and doubtful were considered on evaluation criteria. The present study showed doubtful outcome may possibly be due to lack of proper biomechanical preparation or failure to achieve hermatic seal of root canal system. Also may possibly be due to the comparatively short observation time used. The 18 months follow-up may not have been enough for large lesion to heal. Histologically some areas of periradicular periodontitis need 4 to 5 years to heal ${ }^{24}$.

\section{Conclusion}

On the basis of the results obtained, it may be concluded that endodontically involved teeth with periradicular pathosis (e.g. granuloma, cysts etc) can be managed by non-surgical conventional root canal therapy. And it is the proper biomechanical preparation and hermetic obturation which decide the success of the root canal treatment.

Though the study performed clinically and radiologically, a histological evaluation with a larger sample size and longer follow up period is necessary to reach a sound conclusions.

\section{References:}

1. Torabinazad M. Mediators of pulpal and periapical pathosis. Calif Dent Ass J 1986:14-21

2. Torabinejad M, Walton RE. Periradicular lesions. In: Ingle JI, Bakland LK, editors. Endodontics. Hamilton Ontario: BC Decker; 2002. p. 175-201.

3. Fish EW. Bone infection. J Am Dent Assoc 1939; 26: 691.

4. Simon JHS. Incidence of periapical cysts in relation to the root canal. J Endod 1980; 6: 845.

5. Nair PNR, Pajarola G, Schroeder HE. Types and incidence of human periapical lesions obtained with extracted teeth. Oral Surg Oral Med Oral Pathol. Oral Radiol Endod 1996; 81: 93.

6. Suchina JA, Levine D, Flaitz CM, Nichois CM, Hicks MJ. Retrospective clinical and radiologic evaluation of nonsurgical endodontic treatment in human immunodeficiency virus (HIV) infection. J cContemp Dent Pract 2006; 15(1): 1-8.

7. Bal CS, Sikri VK, Agrawal R. Efficacy of various eugenol and non-eugenol root canal sealers in the treatment of teeth with periapical radiolucent area-A clinical and radiological study. Indian J Dent 1990; 1: 133-138.

8. GreenTL. Radiographic and histologic periapical findings of root canal treated teeth in cadaver. repair after endodontic treatment. Oral Surg 1997; 83: 707.

9. Amler $\mathrm{MH}$. The time sequence of tissue regeneration in human extraction wounds. Oral Surg 1969;27:309.

10. Fouad AF, Walton RE, Rittman BR. Healing of induced periapical lesions in ferret canines. J Endod 1993; 19: 123.

11. Johnson BR, Remeikis N, Vancura J. Diagnosis and treatment of cutaneous facial sinus tracts of dental origin. J Am Dent Assoc 1999; 130: 832. 
12. Nair PNR, Sjogren U, Schumacher F, Sundqvist G. Radicular cysts affecting a root-filled human tooth: A long-term post treatment follow-up. Int Endod J 1993; 26: 225.

13. Nair PNR. Review: new perspectives on radocular cysts: do they heal? Int Endod J 1998; 31: 155.

14. Caliskan MK. Prognosis of large cyst-like periapical lesions following nonsurgical root canal treatment: a clinical review. Int Endod J 2004; 37(6): 408-16.

15. Caliskan MK, Sen BH. Endodontic treatment of teeth with apical periodontitis using calcium hydroxide: a long-term study. Endod Dent Traumatol 1996; 12 (5): 215 -21.

16. Katebzadeh N, Sigurdsson A, Trope M. Radiographic evaluation of periapical healing after obturation of infected root canals: an in vivo study. Int Endod J 2000; 33(1): 60-6.

17. Peters LI, Wesselink PR. Periapical healing of endodontically treated teeth in one and two visits obturated in the presence or absence of detectable microorganisms. Int Endod J 2002; 35(8): 660-7.
18. Kalaskar R, Tiku A, Damle SG. Periapical repair and apical closure of a pulpless tooth using calcium hydroxide-a case report. Indian Soc Pedod Prev Dent 2004; 22(3): 158-61.

19. Oztan MD. Endodontic treatment of teeth associated with a large periapical lesion. Int Endod J 2002; 35(8): 73 -8.

20. Soares J, Santos S, Silveria F, Nunes E. nonsurgical treatment of extensive cyst-like periapical legsion of endodontic origin. Int Endod J 2006; 39(7): 566 -75.

21. Maalouf M, Gutmann JL. Biological prospectives on the nonsurgical endodontic management of periradicular pathosis. Int Endod J 1994; 27(3): 154 -62.

22. Kerekes K, Tronstad L. Long-term results of endodon treatment performed with standardized technique. J Endod 1979; 5: 83.

23. Barbakow FH, Cleaton-jones PE, Friedman D. Endodontic treatment of teeth with periapical radiolucent areas in general dental practice. Oral Surg Oral Med Oral Pathol Oral Radiol Endod 1981; 651: 552.

24. Grecca FS, Leonardo MR, Da Silva LAB Filho MT, Borges MAG. Radiographic evaluation of periradicular repair after endodontic treatment of dog's teeth with induced periradicular periodontitis. J Endod 2001; 27(10): 610-612. 